\title{
The Introspection of Traditional Mentoring Functions and Modification of the Corresponding Scale
}

\author{
Yin-Che Chen \\ Graduate Institute of Human Resource and eLearning Technology \\ National Hsinchu University of Education \\ Hsinchu, Taiwan \\ yinchechen@mail.nhcue.edu.tw
}

\begin{abstract}
With the identification of millennial professional characteristics and advancing information technology (IT), traditional mentoring relationships and methods are gradually shifting toward a reverse-mentoring system. This study reviewed a scale on traditional mentoring functions from the combined perspectives of reverse mentoring and millennial professional characteristics in Taiwan. The results provide organizations with a reference for quantitative evaluations when they promote and execute reverse mentoring. Finally, the proposed scale establishes an empirical foundation to quantify reverse-mentoring systems.
\end{abstract}

Keywords- reverse mentoring; mentoring functions; exploratory factor analysis

\section{INTRODUCTION}

According to the Report on the Manpower Utilization Survey by the Taiwanese Directorate General of Budget, Accounting, and Statistics (Directorate General of Budget, 2011), employees in Taiwan have demonstrated increasing education levels among young-, middle- and old-aged workers. Compared with the data from 2002 to 2012, educational attainment of senior (vocational) high school and college, university \& graduate school increased by $0.4 \%$ and $5.33 \%$ respectively. Nonetheless educational attainment of or under junior high school decreased by $6.71 \%$. On the other hand, labor force participation among 25-44 year-olds significantly increased by $6.36 \%$, but the number for $45-64$ year-olds and 65 year-olds and over slightly increased by $1.44 \%$ and $0.31 \%$ respectively. On the gender distribution, the number of females increased by $3.6 \%$ but that of males decreased by $1.39 \%$. In addition, based on a 2012 Survey of Labor and Employment Life from Council of Labor Affairs, the working landscape in Taiwan consisted of the following characteristics: employees' attendance for training increased up to $48.4 \%$; due to the accountability, $50.7 \%$ of employees had extended working hours. Both data above indicates that the number of Taiwanese employees that belong to generation $\mathrm{X}, \mathrm{Y}, \mathrm{Z}$ has increased continually, and that most baby-boomers still continue to work.

Mentoring has attracted increasing attention from business, education, and the public sector, and has been widely implemented among these organizations in recent years; mentoring relationships not only provide channels for on-thejob training, skill and experience transfers, and educational training, but also fulfill employee psychological contracts and ensure future career development. Traditional mentoring refers to the system in which junior or new employees learn from senior employees within an organization. However, with generation $\mathrm{Z}$ emerging in the workplace and the advancement in IT, traditional mentoring in integrated-circuit design and industrial personal computer in Taiwan has found an alternative in reverse mentoring. Thus, Murphy (2012) defined reverse mentoring as "the pairing of a younger, junior employees as the mentor to share knowledge with an older, senior colleague as the mentee" (P.551).

The reverse-mentoring concept was first promulgated and formally implemented by Jack Welsh, the chairman of General Electric (GE), in 1999 (Quast, 2011, March). Welsh required 500 upper-level managers at GE to learn how to use the Internet from young employees. Subsequently, with IT advances, reverse mentoring, in which junior employees share modern concepts and information media technologies with senior employees, has gradually gained popularity among international and multinational companies. For example, IBM, which is globally listed among top training companies, and the public relations company, Burson-Marsteller, established formal reverse-mentoring systems in their organizations (Meister \& Willyerd, 2010, May).

Based on the aforementioned background and significance of research on reverse mentoring, a scale on traditional mentoring functions would be reviewed from the reverse mentoring perspective in conjunction with the work characteristics of millennials.

\section{LITERATURE REVIEW}

\section{A. Work Characteristics of Baby-Boomers and Millennials}

To begin with, the typical characteristics of baby-boomers included their value in individuality, self-fulfillment, integrity, building consensus and effecting change, intent to make differences, putting their stamp on organizations, and embracing a psyche of entitlement (Smola \& Sutton, 2002; Twenge, Campbell, Hoffman, \& Lance, 2010).

On the other hand, according to the Chen's (2013) empirical study, millennials displayed IT competency, abundant learning resources, innovative thinking and willingness to take risks, teamwork, and communication and coordination skills. These characteristics are described in detail as follows. 


\section{B. Traditional Mentoring Functions}

Levinson (1978) first proposed that traditional mentoring positively influences psychological and career developments. Kram's (1985) perspective regarding traditional mentoring is most influential; he defined mentoring as a relationship pattern in which senior employees guide the junior employees in their organization. Noe (1988) further categorized mentoring functions into career development and psychological support. Career development emphasizes that junior employees can enhance their promotion within the organization by considering the counsel and guidance of senior employees. Psychological support underscores that senior employees enhance the psychological contracts of junior employees. Subsequently, Scandura (1992)and Scandura and Ragins(1993) extracted role modeling in psychological support as a third dimension of mentoring function.

Empirical studies on mentoring indicated that a high level of approval between the mentor and mentee increases the effectiveness of the mentoring relationship (Wu, Tsai, Chang, \& Zhuang, 2007; Wu, Wen, \& Lu, 2009). The pattern of subordination between the mentor and mentee primarily comprises the supervisor-subordinate or mentor-mentee relationship. Studies related to traditional mentoring have investigated whether these relationships are formal or informal (Allen, Russell, \& Maetzke, 1997), direct or indirect (Burke, McKenna, \& McKeen, 1991), the relationship development (Kram, 1985; Levinson, 1978), pairing in the relationship (Burke et al., 1991; Hunt \& Michael, 1983), power exchange in the relationship (Auster, 1984), and the interpersonal network relationship (Clutterbuck, 1992; Higgins \& Kram, 2001). In addition, the systematic implementation of mentoring in an organization strengthens the positive influence of mentoring compared to non-systematic mentoring (Allen, Eby, \& Lentz, 2006; Parise \& Forret, 2008; Wanberg, Kammeyer-Mueller, \& Marchese, 2006; Zeind et al., 2005).

Moreover, empirical studies have suggested significant causal relationships between the mentoring functions of career development and psychological support. The subsequently discussed empirical studies separately describe career development and psychological support, and role modeling.

\section{Reverse Mentoring}

Currently, the only Taiwanese empirical study on reverse mentoring is a 2011 National Science Council qualitative project research proposal titled "Effect of Reverse Mentoring on Traditional-Mentoring Functions" (Y. C. Chen, 2013). By using purposive sampling and the multi-case study design proposed by Yin (1994), this study explored organizations in high-tech Taiwanese industries that implemented reverse mentoring. The results were divided into three mentoring functions:

\section{Career Development}

Reverse mentoring refers to the relationship pattern in which junior, low-level, or younger employees guide senior, mid- to high-level, or older employees. The results indicated that the implications of traditional mentoring, such as teaching, providing challenges, exposures, and visibility, remain in reverse-mentoring. However, because of the replacement of the subordination relationship, the protection implication of traditional mentoring is substituted with the management implication of career development, which concurs with Murphy's (2012) viewpoint. That said, possibly due to the cultural and contextual differences, available studies on reverse mentoring that occurred in the American workforce suggested a few different inclusions in career development, which are knowledge sharing, coaching, exposure and visibility, skill development, changing ideas, networking (W. M. Murphy, 2012) and social affiliation (Chaudhuri \& Ghosh, 2012).

\section{E. Psychological Support}

Previous studies claimed that the traditional mentoring implications, such as acceptance, guidance, counseling, and friendship, were preserved in reverse mentoring. Besides, if the mentor could consider reverse mentoring perceived positively with organizational support and leader-member exchanges, mentors would increase their engagement and organizational commitment at work (Chaudhuri \& Ghosh, 2012). Nonetheless, the approval implication does not exist in reverse mentoring because of the age and job-level differences between the mentor and the mentee. Finally, Murphy (2012) further stated that a few implications in psychological support of reverse mentoring should be incorporated, such as affirmation, encouragement, and feedback.

\section{F. Role Modeling}

Regarding the three mentoring functions, the results indicated that role modeling more significantly influenced reverse mentoring than career development or psychological support, especially when the mentor engages in a high-quality leader-member exchange with the mentee (Chaudhuri \& Ghosh, 2012). Although senior employees (mentees) might doubt the trust and respect that their younger/ junior mentors display, their work efficiency, learning standards (Y. C. Chen, 2013), and perspectives, according to Murphy (2012), were improved.

\section{G. Modifications of the Traditional-Mentoring Functioning Scale}

The original version of the scale on traditional mentoring functions comprised three dimensions (15 questions): career development (six questions with a Cronbach's $\alpha$ value of .86), psychological support (five questions with a Cronbach's $\alpha$ value of .88), and role modeling (four questions with a Cronbach's $\alpha$ value of .84 ). The modified scale based on the empirical study by Chen (2011) still possessed the three mentoring function dimensions; however, two questions were added to the career development dimension (totaling eight), two were added to psychological support (totaling six), and one was added to role modeling (totaling five), for a total of 19 questions.

\section{RESULTS AND ANALYSIS}

\section{A. Research Participants}

With the purposive sampling, this study selected mentors and mentees from Taiwanese organizations which have already adopted reverse mentoring for data collection with the modified scale above. Two targets were integrated-circuit design companies and one an industrial personal computer corporation. Among the 158 valid samples, the average age of the participants was 36.71 years. The percentage of non-managers was $61.4 \%$. The average number of years in the current 
position was 7.09 years and the average total years of employment was 12.98 , with an average number of 3.37 years as mentoring experiences and $58.9 \%$ of the participants being the mentee. In addition, the correlation coefficients of the reverse-mentoring subscales ranged from .631 to $.776(\mathrm{p}<.01)$, indicating that the items possessed intermediate to high levels of internal consistency.

\section{B. Limitation}

The research target of this study focused on IT companies which have already adopted reverse mentoring in Taiwan. Thus, the implications of this study may not be fully applicable in other industries.

\section{Scale Reliability and Validity}

Cronbach's $\alpha$ and extracted variance were used to assess the reliability of the scale. The convergent and discriminant validities were examined using an exploratory factor analysis to assess the scale validity.

Cronbach's $\alpha$ values of the overall reverse-mentoring system and its three functions were $.959, .916, .851$, and .955 , indicating high internal consistency and stability between the scale and each dimension. The Kaiser-Meyer-Olkin value of the reverse-mentoring scale was .929 and the Bartlett's sphericity test attained significance $(p<.001)$. After reassigning Item 6 of the career development subscale to role modeling, the factor loading of career development was between .653 and .766 . After reassigning Items 5 and 6 of the psychological support subscale to role modeling, the factor loading of psychological support was between .626 and .851 . Role modeling comprises 8 items, attaining a factor loading between .568 and .836 . The explained variance of the overall scale was $58.45 \%$, attaining a $72.81 \%$ cumulative explained variance. These statistics show that the proposed scale possesses exceptional reliability and validity.

Subsequently, the researcher adopted Amos 18 to conduct an exploratory factor analysis, using the $\mathrm{Wu}$ and $\mathrm{Tu}$ (2008) goodness-of-fit model as the test standard $(\mathrm{p}>.5$, GFI $>.90$, AGFI $>.90$, NFI $>.90$, CFI $>.90$, RMR $<.05$, RMSEA $<.008)$. The data shows that all values of the model satisfy the goodness-of-fit criteria $(\chi 2=169.319, \mathrm{df}=126, \mathrm{p}=.006, \mathrm{GFI}$ $=.909, \mathrm{AGFI}=.862, \mathrm{NFI}=.940, \mathrm{CFI}=.984, \mathrm{RMR}=.057$, RMSEA $=.047$ ), indicating that the model for the reversementoring scale possesses excellent goodness-of-fit. Discussion.

\section{DISCUSSION}

Traditional mentoring relationships in an organization engender positive influences among career development, psychological support, and role modeling in relation to mentees, thereby reducing their work pressure and likelihood to resign, improving work performance, enhancing individual and organizational socialization, and mitigating work-family conflicts. Although reverse mentoring, which is derived from millennial work characteristics, maintains the three dimensions of mentoring function (i.e., career development, psychological support, and role modeling), the corresponding implications are adjusted. The protection implication of the career development function is replaced by management. The approval implication of psychological support is removed, and the trust and respect implications of role modeling are challenged by mentees. Mentees in reverse-mentoring relationships may possess more years of employment and relatively extensive interpersonal networks in the organization, which substantially reduces their perceptions of the protection, approval, trust, and respect of their mentors. Mentees expect their mentors to incorporate innovative thoughts and IT literacy into the mentoring behavior Simultaneously, the high standard implication of role modeling is strengthened for the mentor, increasing the work efficiency and learning standards of the mentee.

After exploring the work characteristics of millennials and comparing reverse and traditional mentoring, the scale on traditional mentoring functions was modified, retaining the three original dimensions. The modified scale was as follows: (a) one item was removed from the career development dimension and three were added; (b) one item was removed from the psychological development dimension and two were added; and (c) one item was removed from the role modeling dimension and two were added. The modified scale comprised 19 items.

Subsequently, the researcher used purposive sampling to recruit mentors and mentees from Taiwanese organizations that implemented reverse mentoring for a scale survey. The results indicated that the correlation coefficients of the subscales ranged from .631 to $.776(p<.01)$, attaining intermediate to high levels of internal consistency. Cronbach's $\alpha$ values of the overall reversementoring system and the three functions were $.959, .916, .851$, and .955 , respectively, indicating a high level of stability between the scale and dimensions. Through factor analysis, after Item 6 of the career development subscale was reassigned to role modeling, the factor loading of career development was between .653 and .766. After Items 5 and 6 of the psychological support subscale were reassigned to role modeling, the factor loading of psychological support was between .626 and .851 . Role modeling comprised 8 items in total, attaining a factor loading between .568 and .836. The explained variance of the overall scale was $58.45 \%$, attaining a $72.81 \%$ cumulative explained variance. Finally, an exploratory factor analysis was performed to examine the model goodness-of-fit. The data showed that the reverse-mentoring scale possessed exceptional model goodness-of-fit $(\chi 2=169.319$, $\mathrm{df}=$ $126, \mathrm{p}=.006, \mathrm{GFI}=.909, \mathrm{AGFI}=.862, \mathrm{NFI}=.940, \mathrm{CFI}=.984$, $\mathrm{RMR}=.057, \mathrm{RMSEA}=.047)$.

The empirical results of this study should encourage organizational managers to allocate attention to reverse mentoring and systematize reverse mentoring with the assistance of the human resource department. Organizations can combine their existing educational training specifications and systems to gradually implement semi-formal or informal reverse-mentoring systems; consequently, management problems resulting from the generational gap among employees in medium- and large-scale Taiwanese enterprises can be improved. Furthermore, the proposed scale marks the emergence of reverse-mentoring quantitative research as a topic of concern in academic research.

\section{REFERENCES}

[1] Allen, T. D., Eby, L. T., \& Lentz, E. (2006). Mentorship behaviors and mentorship quality associated with formal mentoring programs: Closing the gap between research and practice. Journal of Applied Psychology, 91(3), 567-578. doi: 10.1037/0021-9010.91.3.567 
[2] Allen, T. D., Russell, J. E., \& Maetzke, S. B. (1997). Formal peer mentoring: Factors related to protégés satisfaction and willingness to mentor others. Group and Organization Management, 22(4), 488-507.

[3] Alvarez, D. M., Blair, K., Monske, E., \& Wolf, A. (2005). Team models in online course development: A unit-specific approach. Educational Technology and Society, 8(3), 176-186.

[4] Auster, D. (1984). Mentors and protégés: Power-dependent dyads. 54(2), 142153

[5] Burke, R. J., McKenna, C. S., \& McKeen, C. (1991). How do mentorships differ from typical supervisory relationships? Psychological Reports, 68(2), 459-466.

[6] Chaudhuri, S., \& Ghosh, R. (2012). Reverse mentoring: A social exchange tool for keeping the boomers engaged and millennials committed. Human Resource Development Review, 11(1), 55-76. doi: $10.1177 / 1534484311417562$

[7] Chen, Y. C. (2013). Effect of reverse mentoring on traditional-mentoring functions. Leadership and Management in Engineering, 13(3), 1-10.

[8] Chen, Y. S., \& Hsieh, Y. C. (2008). The impact of mentoring functions on job performance: The mediating effect of personal learning in the workplace. Chung Cheng Educational Studies, 7(2), 65-91.

[9] Clutterbuck, D. (1992). Everyone needs a mentor. London, UK: IPM.

[10] Cotugna, N., \& Vickery, C. E. (1998). Reverse mentoring: A twist to teaching technology. Journal of the American Dietetic Association, 98(10), 1166-1168. doi: 10.1016/s0002-8223(98)00270-3

[11] Directorate General of Budget, A. a. S., Executive Yuan. (2011). Manpower utilization survey. Retrieved from http://www.stat.gov.tw/public/Attachment/111291613371.pdf

[12] Higgins, M. C., \& Kram, K. E. (2001). Reconceptualizing mentoring at work: A developmental network perspective. Academy of Management Review, 26(2), 264-288.

[13] Hsu, P. C., \& Lan, P. T. (2008). The effects of mentoring on new salesperson' turnover intention in life insurance industry: A mediating approach of organization socialization content. Chaoyang Business and Management Review, 7(1), 27-50.

[14] Hunt, D. M., \& Michael, C. (1983). Mentorship: A career training and development tool. Academy of Management Review, 8(3), 475-485.

[15] Kram, K. E. (1985). Mentoring at work. Glenview, IL: Scott Foresman.

[16] Leh, A. S. C. (2005). Lessons learned from service learning and reverse mentoring in faculty development: A case study in technology training. Journal of Technology and Teacher Education, 13(1), 25-41.

[17] Levinson, D. J. (1978). The seasons of a man's life. New York, NY: Simon \& Schuster.

[18] Li, A. T., \& Hung, Y. P. (2009). The relationship between mentoring functions and job performance: The mediating role of self-efficacy. Journal of Human Resource Management, 9(1), 23-43.

[19] Lin, Y. L., \& Chang, w. J. (2010). The mediating effect of the organizational socialization on mentoring: Job stress relationship. Journal of Human Resource Management, 10, 75-96.

[20] Louis, M. R. (1980). Surprise and sense making: What newcomers experience in entering unfamiliar organizational settings. Administrative Science Quarterly, 25(3), 226-251.

[21] McCauley, C. D., \& Young, D. P. (1993). Creating developmental relationships: Roles and strategies. Human Resource Management Review, 3, 219-230.

[22] Meister, J. C., \& Willyerd, K. (2010, May). Mentoring millennials. Harvard Business Review.

[23] Mullen, E. J. (1994). Framing the mentoring relationship as an information exchange. Human Resource Management Review, 4, 257-281.

[24] Murphy, J., \& Adams, A. (2005). Exploring the benefits of user education: A review of three case studies. Health Information \& Libraries Journal, 22(s1), 45-58. doi: 10.1111/j.1740-3324.2005.00585.x

[25] Murphy, W. M. (2012). Reverse mentoring at work: Fostering crossgenerational learning and developing millennial leaders. Human Resource Management, 51(4), 549-574. doi: 10.1002/hrm.21489
[26] Noe, R. A. (1988). An investigation of the determinants of successful assigned mentoring relationships. Personnel Psychology, 41, 457-479.

[27] Parise, M. R., \& Forret, M. L. (2008). Formal mentoring programs: The relationship of program design and support to mentors' perceptions of benefits and costs. Journal of vocational behavior, 72(2), 225-240. doi: 10.1016/j.jvb.2007.10.011

[28] Quast, L. (2011, March). Reverse mentoring: What it is and why it is beneficial. Work in Progress. Retrieved from http://www.forbes.com/sites/work-in-progress/2011/01/03/reversementoring-what-is-it-and-why-is-it-beneficial/

[29] Ragins, B. R., \& McFarlin, D. B. (1990). Perceptions of mentor roles in cross-gender mentoring relationships. Journal of Vocational Behavior, 37, 321-339.

[30] Rhodes, J. E., Contreras, J. M., \& Mangelsdorf, S. C. (1994). Natural mentor relationships among Latina adolescent mothers: Psychological adjustment, moderating processes, and the role of early parental acceptance. American Journal of Community Psychology, 20(2), 445461.

[31] Rhodes, J. E., Ebert, L., \& Fischer, K. (1992). Natural mentors: An overlooked resource in the social networks of young African American mothers. American Journal of Community Psychology, 22(4), 211-227.

[32] Scandura, T. A. (1992). Mentorship and career mobility: An empirical investigation. Journal of Organizational Behavior, 13(2), 169-174.

[33] Scandura, T. A., \& Ragins, B. R. (1993). The effects of sex and gender tole orientation on mentorship in male-dominated occupations. Journal of Vocational Behavior, 43(3), 251-265.

[34] Smola, K. W., \& Sutton, C. D. (2002). Generational differences: Revisting generational work values from the new millennium. Journal of Organizational Behavior, 23, 363-382.

[35] Sosik, J. J., \& Godshalk, V. M. (2000). The role of gender in mentoring: Implications for diversified and homogenous mentoring relationships. Journal of Vocational Behavior, 57(1), 102-122.

[36] Teng, H. M. (2005). A study of the influence of mentor function on the work-family conflict. Commerce \& Management Quarterly, 6(3), 335356

[37] Twenge, J. M., Campbell, S. M., Hoffman, B. J., \& Lance, C. E. (2010). Generational differences in work values: Leisure and extrinsic values increasing, social and intrinsic values decreasing. Journal of Management, 36, 1117-1142.

[38] Van Maanen, J., \& Schein, E. H. (1979). Toward a theory of organizational socialization. Research in Organizational Behavior, 1, 209-264.

[39] Wanberg, C. R., Kammeyer-Mueller, J., \& Marchese, M. (2006). Mentor and protege predictors and outcomes of mentoring in a formal mentoring program. Journal of Vocational Behavior, 69(3), 410-423. doi: 10.1016/j.jvb.2006.05.010

[40] Wu, M. L. (2002). The study of mentoring relationship to the women in charge of the work on work adaption, promotion and salary satisfaction. Taipei: National Science Council.

[41] Wu, M. L., Tsai, M. Y., Chang, C. C., \& Zhuang, W. L. (2007). Relationship between mentoring functions and organizational socialization: An example of military officers. Journal of Human Resource Management, 7(2), 71-92.

[42] Wu, M. L., Wen, S. L., \& Lu, C. C. (2009). Elucidating the relationship between peer mentoring and learning effectiveness for undergraduates. Chung Yuan Management Review, 7(2), 117-141.

[43] Yin, R. K. (1994). Case study research design and methods (3rd ed.). Thousand Oaks, CA: Sage.

[44] Yu, C., Yu, C. C., Yu, T. F., Cheng, Y. S., \& Tseng, C. C. (2011). An example of $3 \mathrm{C}$ after-sale service of the key success factors and effect on career development of mentoring. Chung Hua Journal of Management, 12(1), 39-72.

[45] Zeind, C. S., Zdanowicz, M., MacDonald, K., Parkhurst, C., King, C., \& Wizwer, P. (2005). Developing a sustainable faculty mentoring program. American Journal of Pharmaceutical Education, 69(5), 1-13. 